\title{
DIFERENCIAL DE RENDIMENTOS ENTRE EMPREENDEDORES E ASSALARIADOS: UMA ANÁLISE PARA A REGIÃO SUL DO BRASIL
}

\author{
Roque Pinto de Camargo Neto ${ }^{1}$ \\ Vivian dos Santos Queiroz Orellana ${ }^{2}$ \\ Gabrielito Rauter Menezes ${ }^{3}$
}

Resumo: O objetivo deste estudo é analisar o diferencial de rendimentos dos empreendedores e assalariados na região Sul do Brasil, tendo em vista a importância desse assunto para que se possam realizar políticas públicas eficientes em relação aos incentivos ao empreendedorismo. Para isso, utiliza-se a base de dados da Pesquisa Nacional de Amostras por Domicílios (PNAD-2015) do Instituto Brasileiro de Geografia e Estatística (IBGE). O método utilizado consiste em um modelo probabilístico com distribuição normal (probit) bem como um modelo para a correção do viés de seleção (heckit). Por fim, os resultados apontam que o empreendedor da região Sul aufere, em média, remuneração maior que um indivíduo aleatoriamente distribuído na amostra.

Palavras-chave: Empreendedorismo. Empreendedorismo Regional. Diferencial de Rendimentos. Renda dos Empreendedores. Decisão Ocupacional.

\section{INCOME DIFFERENTIAL BETWEEN ENTREPRENEURS AND EMPLOYED WORKERS: AN ANALYSIS FOR THE SOUTHERN REGION OF BRAZIL}

Abstract: The objective of this study is to analyze the income differential of entrepreneurs and wage earners in the South region of Brazil, considering the importance of this subject so that efficient public policies can be realized in relation to incentives to entrepreneurship. For this purpose, the National Survey of Household Survey (PNAD-2015) database of the Brazilian Institute of Geography and Statistics (IBGE) is used. The method used consists of a probabilistic model with normal distribution (probit) as well as a model for the correction of the selection bias (heckit). Finally, the results indicate that the entrepreneur in the South region receives, on average, a higher remuneration than an individual randomly distributed in the sample.

Keywords: Entrepreneurship. Regional Entrepreneurship. Income Differential. Entrepreneurs' Income. Occupational Decision.

\section{DIFERENCIAL DE INGRESOS ENTRE EMPRESARIOS Y EMPLEADOS: UN ANÁLISIS PARA LA REGIÓN SUR DEL BRASIL}

Resumen: El objetivo de este estudio es analizar el diferencial de ingresos de los empresarios y los asalariados en la región sur de Brasil, considerando la importancia de este tema para que se puedan realizar políticas públicas eficientes en relación con los incentivos al espíritu empresarial. Para ello, se utiliza la base de datos de la Encuesta Nacional de Muestras de Hogares (PNAD-2015) del Instituto Brasileño de

\footnotetext{
1 Escola Superior de Administração, Marketing e Comunicação, Escola de Negócios, Sorocaba, Brasil, roquecneto@usp.br, https://orcid.org/0000-0003-0959-3634

2 Universidade Federal do Rio Grande, Instituto de Ciências Econômicas, Administrativa e Contábeis, Rio Grande, Brasil, viviansq13@gmail.com.br, https://orcid.org/0000-0002-6626-061X

3 Universidade Federal de Pelotas, Departamento de Ciências Sociais Agrárias, Pelotas, Brasil, gabrielitorm@gmail.com.br, https://orcid.org/0000-0001-7649-5132
} 
Geografía y Estadística (IBGE). El método utilizado consiste en un modelo probabilístico con distribución normal (probit), así como un modelo para la corrección del sesgo de selección (heckit). Finalmente, los resultados indican que el empresario en la región Sur gana, en promedio, una remuneración más alta que un individuo distribuido al azar en la muestra.

Palabras clave: Emprendimiento. Emprendimiento Regional. Diferencial de ingresos. Ingresos de emprendedores. Decisión ocupacional.

\section{Introdução}

A relação entre a atividade empreendedora e o crescimento econômico tem sido muito relevante para os debates acadêmicos, assim como Acs e Armington (2004) sugerem, que as teorias de crescimento econômico devem dar atenção ao empreendedorismo, para entender melhor os transbordamentos do conhecimento em uma economia regional, além disso, apresentam resultados significativos de que taxas mais elevadas de atividade empreendedora foram fortemente correlacionadas a um crescimento mais rápido de economias locais nos EUA. Em contraponto, Fritsch e Mueller (2007) apontam que novos negócios podem ter impactos positivos e negativos para uma região, de forma que nesse estudo o foco está na geração de empregos em regiões da Alemanha, portanto, evidenciam que em regiões de baixa produtividade, o efeito global de emprego da formação de novos negócios pode ser negativo.

Alguns estudos convergem no sentido de mostrar que há relação entre o empreendedorismo e o crescimento econômico, assim como Audretsch e Thurik (2001), que retratam através de uma análise empírica, por uma cross-section de países sobre um ponto no tempo, que aqueles países que tiveram uma maior mudança para uma economia empresarial obtiveram níveis mais baixos de desemprego. Assim como, Carree e Thurik (2005) avaliam os impactos de mudanças no número de proprietários de negócios sobre o crescimento do emprego, crescimento econômico e aumento de produtividade do trabalho para países da OCDE, cujo resultado reflete um efeito positivo para o emprego e o crescimento econômico, sobre a produtividade do trabalho não obtiveram efeitos.

Segundo Almeida, Sediyama e Santiago (2015) o empreendedorismo é um fator de crescimento econômico para o Brasil, seja por inovação ou pela criação de novos negócios. Além disso, Menezes, Queiroz e Feijó (2015) apontam que os empreendedores possuem maiores rendimentos do que os assalariados no país. Além disso, Bock e Wagner (2010) apontam que os empreendedores por 
oportunidade e por necessidade, na Alemanha, apresentam diferentes características socioeconômicas, bem como um diferencial no rendimento. Tendo isso em vista, e dada a importância do tema para questões econômicas e sociais, relatada em estudos sobre empreendedorismo, como pode ser visto em Carree e Thurik (2005), Parker (2009), e Oosterbeek, Van Praag e ljsselstein (2010), busca-se por meio deste estudo avaliar o diferencial de rendimentos entre as ocupações empreendedoras e assalariadas na região Sul do Brasil. Tendo em vista a importância de se compreender questões sobre rendimentos entre ocupações no mercado de trabalho, para que assim possa-se realizar políticas públicas mais eficientes, além do que, seja possível encontrar os incentivos adequados para estimular a atividade empreendedora na região. Assim como constatado por Camargo Neto et al. (2017), há diferenças regionais sobre a influência de questões socioeconômicas e a atividade empreendedora. O que justifica a importância de uma análise regional do diferencial de rendimentos, para que seja possível obter maior precisão nos resultados e nas futuras políticas públicas.

Portanto, o objetivo deste estudo é avaliar o diferencial de rendimentos entre empreendedores e assalariados, bem como os efeitos de variáveis socioeconômicas sobre a decisão ocupacional. Para isso, utiliza-se a base de dados da Pesquisa Nacional por Amostra de Domicílios (PNAD) de (2015), elaborada pelo Instituto Brasileiro de Geografia e Estatística (IBGE), cujos dados apontam que o salário médio dos empreendedores na região Sul do país é $60 \%$ maior do que o salário médio dos assalariados. Para avaliar o diferencial nos rendimentos utiliza-se o modelo de Heckman (1979), com o objetivo de corrigir o possível viés de seleção na estimação das equações, bem como um modelo probit para estimar a relação entre as variáveis socioeconômica e a decisão ocupacional empreendedora.

\section{Referencial Teórico}

Durante as primeiras décadas do século passado, as pequenas empresas foram um veículo para o empreendedorismo e uma fonte de emprego e renda. Esta é a época em que Schumpeter escreveu "A Teoria do Desenvolvimento Econômico", enfatizando o papel do empreendedor como principal causa do desenvolvimento econômico. Ele descreve como o empreendedor inovador desafia as empresas já estabelecidas através da introdução de novas invenções que fazem produtos e tecnologias atuais obsoletos. Este processo de destruição criativa é a principal 
característica que tem sido chamado o regime de Schumpeter (CARREE; THURIK, 2005).

O empreendedorismo tem sido um tema atual na discussão sobre crescimento econômico, bem como Parker (2009) retrata que veio a ser um campo de estudo recentemente, além disso avança rapidamente sobre insights de como 0 empreendedorismo interage com a economia. Essa questão também é abordada por Rees e Shah (1986) como sendo o auto-emprego uma alternativa para o emprego, assim ampliando a frente de escolha tanto para o candidato potencial ao mercado de trabalho como para os desempregados. Entretanto, Fritsch e Mueller (2007) detectam os efeitos da formação de novos negócios sobre o desenvolvimento regional na Alemanha, cujo resultado é que há um aumento no emprego regional no curto prazo, após um ou dois anos ocorre uma redução do emprego por meio da saída de empresas não competitivas do mercado, no entanto a concorrência pode proporcionar ganhos de produtividade.

Policy-makers da Europa e dos Estados Unidos acreditam que mais empreendedorismo é necessário para atingir maiores níveis de crescimento econômico e inovação. De fato, a pesquisa empírica suporta ligações positivas entre a atividade empresarial e resultados econômicos, tais como crescimento econômico e inovação (VAN PRAAG; VERSLOOT, 2007). Tamvada (2007) avalia os efeitos do empreendedorismo em retornos de consumo na Índia, mostrando que empregadores têm retornos mais altos em termos de consumo, enquanto trabalhadores autônomos que não empregam apresentam retornos levemente mais baixos do que trabalhadores assalariados. Esta evidência sugere que o auto-emprego não é a melhor opção de trabalho em relação ao trabalho assalariado.

Além de discussões ao redor dos efeitos econômicos, alguns estudos investigam o impacto da educação para habilidades de empreendedorismo em estudantes, como é o caso de (Oosterbeek, Van Praag e ljsselstein (2010); Lorz (2011); Huber, Sloof e Van Praag (2012)). Nestes estudos encontram-se resultados semelhantes no que diz respeito à educação empreendedora, apontam para uma ausência de efeitos significativos desse treinamento. Com relação à escolha ocupacional Lazear (2005) aponta que indivíduos com habilidades equilibradas são mais propensos, do que outros, a se tornarem empresários. Além disso, relata que aqueles que têm background entre trabalho e educação são mais propensos a iniciar seus próprios negócios do que aqueles que têm focado em um papel no trabalho ou em um assunto na escola. 
Menezes, Queiroz e Feijó (2015) fazem uma análise do diferencial de rendimentos dos empreendedores e assalariados para o Brasil, e encontram que os empreendedores possuem maiores rendimentos, os autores ainda encontram que há efeito distinto para as regiões no país. Bem como, Camargo Neto et al. (2017) apontam que há heterogeneidade no efeito das condições socioeconômicas sobre a decisão ocupacional, os autores encontram que a renda é uma importante condição para a opção empreendedora e que há regiões cujo efeito da renda sobre a decisão empreendedora é maior do que em outras.

\section{Metodologia}

Nesta sessão trataremos dos métodos utilizados para estimar uma função de probabilidade com distribuição normal probit e das equações de rendimentos, que servem de instrumento para analisar os determinantes do empreendedorismo para a região Sul do Brasil, bem como ressaltará sobre os dados e seus tratamentos.

\section{Método heckit}

Um indivíduo enfrenta um par de escolhas, opta pela opção que lhe proporciona a maior utilidade. Muitas dessas configurações envolvem a escolha entre tomar uma ação e não tomar, por exemplo, a decisão se deve ou não comprar um seguro de saúde. Em outros casos, a decisão pode ser entre duas escolhas distintas, tais como a decisão de viajar a trabalho através de transportes públicos ou privados. No caso escolha binária, o resultado "zero ou um" é apenas um rótulo de "sim ou não", os valores numéricos são uma mera conveniência (GREENE, 2012).

De acordo com Parker (2009) os modelos de escolha binária são amplamente utilizados em estudos sobre empreendedorismo, sendo que os mais comuns são probit e logit, usados para modelar o empreendedorismo como uma escolha ocupacional.

Considere duas ocupações denotadas por $j, E$ indicando empreendedor e $P$ um emprego remunerado qualquer. Cada indivíduo tem um vetor de características observáveis $W_{i}$ e uma função de utilidade $U_{i j}=U\left(W_{i} ; E\right)+u_{i j}$ se eles trabalham na ocupação j; destaca-se que $U(. ;$.$) é a utilidade que pode ser observada através do$ uso da econometria e $u_{i j}$ a utilidade não observada idiossincrática. Denote por $z_{i}^{*}$ uma variável latente que mensura a vantagem da utilidade relativa do indivíduo $i$ na ocupação $E$ em relação a $P$. Isto é, 


$$
z_{1 i}^{*}=U\left(W_{i} ; E\right)-U\left(W_{i} ; P\right)+u_{i E}-u_{i P}
$$

Assumindo que $U(. ;$.$) é linear, e tomando a forma U\left(W_{i} ; j\right)=\beta_{j}^{\prime} W_{i}$, onde $\beta_{j}$ são vetores de coeficientes, então podemos escrever a equação (1) da seguinte forma:

$$
z_{1 i}^{*}=\alpha+\beta^{\prime} W_{i}+v_{i}
$$

onde $\beta^{\prime}:=\beta_{E}^{\prime}-\beta_{p}^{\prime}$ é outro vetor de coeficientes; $\alpha:=E\left[u_{i E}-u_{i p}\right]$ é o termo do intercepto; e $v_{i}:=u_{i E}-u_{i P}-\alpha \sim I I N\left(0, \sigma^{2}\right)$ é o termo de erro. $O$ intercepto é incorporado em $W_{i}$, então $\beta$ vai ser tratado como um conjunto completo de coeficientes. De acordo com Parker (2009), o indivíduo vai escolher ser empreendedor ao invés de ser trabalhador remunerado se $z_{1 i}^{*} \geq 0$. Assim podemos definir a variável binária de escolha ocupacional como:

$$
z_{i}=\left\{\begin{array}{l}
1 \text { se o indivíduo } i \text { é observado em } E \text {, ou seja, se } z_{i}^{*} \geq 0 \\
0 \text { se o indivíduo } i \text { é observado em } P \text {, ou seja, se } z_{i}^{*}<0
\end{array}\right.
$$

Portanto, a probabilidade de um indivíduo ser um empreendedor, em uma amostra representativa, com um vetor característico $W_{i}$ é:

$$
\operatorname{Pr}\left(z_{i}=1\right)=\operatorname{Pr}\left(z_{i}^{*} \geq 0\right)
$$

O modelo probit assume que a distribuição do termo de erro $v_{i}$ é normal. Considerando $\operatorname{Pr}\left(z_{i}=1\right)=\Phi\left(\frac{\beta^{\prime} w_{i}}{\sigma}\right)$ e $\operatorname{Pr}\left(z_{i}=0\right)=1-\Phi\left(\frac{\beta^{\prime} w_{i}}{\sigma}\right)$, onde $\Phi($.$) é a$ função de distribuição cumulativa (FDC) da distribuição normal padrão. Onde $z_{\bar{i}}$ assume valor de 1 se o indivíduo é um empreendedor e zero caso contrário; $W_{i}$ é o vetor de variáveis explicativas contendo diferentes características individuais.

O modelo é estimado utilizando-se 0 procedimento de máxima verossimilhança. $O$ mesmo seleciona estimativas dos parâmetros desconhecidos de modo a maximizar o valor da função de máxima verossimilhança. A função de máxima verossimilhança do modelo probit é dada por: 


$$
\mathcal{L}=\prod_{i=1}^{n} \Phi\left(\frac{\beta^{\prime} W_{i}}{\sigma}\right)^{z_{i}}\left[1-\Phi\left(\frac{\beta^{\prime} w_{i}}{\sigma}\right)\right]^{1-z_{i}}
$$

Onde $\Phi($.$) é a função de distribuição cumulativa;$

Como os coeficientes estimados a partir do estimador de máxima verossimilhança não permitem uma interpretação direta, vamos estimar também o efeito marginal médio, para que tenhamos um resultado que permite uma melhor discussão. O benefício dos efeitos marginais médios é o fato de permitir a análise das implicações quantitativas sobre os coeficientes estimados. Neste caso, o efeito marginal é dado pela seguinte expressão:

$$
\frac{\partial E(z \mid w)}{\partial w}=\phi\left(W_{i} \beta\right) \beta
$$

Onde, $W_{i} \beta$ representa 0 vetor de coeficientes multiplicado por um vetor que contenha valores para as variáveis dependentes. O efeito marginal pode ser interpretado como uma mudança na probabilidade para uma mudança infinitesimal em cada variável independente para as variáveis contínuas e a mudança discreta na probabilidade para variáveis dummies.

Para completar a análise serão estimadas as equações de rendimento (MINCER, 1974), a qual explica a escolha ocupacional empreendedora em função dos ganhos relativos ao trabalho assalariado, através do método proposto por Heckman (1979). Onde a partir do modelo probit univariado computam-se as variáveis de correção para viés de seleção ${ }^{4}$.

A estimativa simples da equação de determinação de salários por mínimos quadrados ordinários poderia causar viés nos coeficientes devido à seletividade da amostra que existe quando apenas os indivíduos empregados entram nos cálculos (KASSOUF, 1994). A seguir, mostra-se as equações de salários mincerianas, em que uma é para indivíduos empreendedores e a outra para assalariados, assim como proposto por Heckman (1979).

Vamos representar os salários por:

\footnotetext{
${ }^{4}$ O viés de seleção surge do problema de atributos não observáveis dos indivíduos. Como por exemplo, sonho de se tornar um empreendedor, a determinação, motivação e o esforço pessoal de cada indivíduo. A desconsideração da heterogeneidade não observada envolvida na condição de empreendedor/assalariado pode fornecer resultados espúrios no que tange as equações de rendimento.
} 


$$
\begin{aligned}
& z_{2 i}=\beta^{\prime} R_{2 i}+v_{2 i} \\
& z_{3 i}=\beta^{\prime} R_{3 i}+v_{3 i}
\end{aligned}
$$

Onde $R_{i}$, é um vetor de variáveis que determina as taxas salariais.

Assim, tem-se duas equações de salários. Assumindo que $v_{2 i}$ e $v_{3 i}$ têm uma distribuição normal bivariada com médias zero, desvios padrão $\sigma_{v_{2 i}}$ e $\sigma_{v_{s i}}$, e correlação $\rho$, então temos que:

$$
E(W i \backslash W i \text { é observado })=E\left(W i \backslash L_{i}^{*}>0\right)=\beta^{\prime} R_{i}+\rho \sigma_{v} \lambda_{i}\left(\alpha_{u}\right)
$$

Por fim, obtém-se as taxas inversas de Mills, através da equação (10): $\lambda_{1} \equiv\left[-\frac{\phi(\hat{P})}{1-\Phi(\hat{P})}\right]$ para os indivíduos assalariados e $\lambda_{2} \equiv\left[\frac{\phi(\hat{P})}{\Phi(\hat{P})}\right]$ para os indivíduos empreendedores, $\phi($.$) é a função de densidade normal padrão e \Phi($.$) é a função de$ densidade normal acumulada (LEE, 1983; MADDALA, 1986). Por fim, os lambdas são incluídos como regressores adicionais nas equações de salários definidas acima, $z_{2 i}$ e $z_{3 i}$.

\section{Diferencial de rendimentos}

Para mensurar o diferencial entre empreendedores e assalariados, tira-se a diferença entre os respectivos rendimentos esperados que foram controlados para autosseleção amostral através do método de Heckman (1979) descrito na subseção anterior. $O$ cálculo do diferencial de renda $D$ é feito da seguinte forma:

$$
D=\hat{y}_{e}-\hat{y}_{a}
$$

Onde $\hat{y}_{\varepsilon}$ e $\hat{y}_{a}$ são os rendimentos dos empreendedores e assalariados, respectivamente, controlados para viés de seleção.

Para calcular a diferença de renda entre empreendedores e assalariados são feitos exercícios contrafactuais. Para obter o rendimento contrafactual do empreendedor caso estivesse na ocupação assalariada são imputados os coeficientes estimados desses últimos (desempenho factual) à amostra de empreendedores. Para obter o rendimento contrafactual dos assalariados, caso 
estivessem ocupados como empreendedores, basta imputar os coeficientes estimados destes últimos (desempenho factual) à amostra de empreendedores.

\section{Base de dados e tratamentos}

Faz-se uso da base de dados ${ }^{5}$ da Pesquisa Nacional de Amostra por Domicílios de 2015 (PNAD-2015), feita pelo Instituto Brasileiro de Geografia e Estatística (IBGE). Para que os dados cumpram com a finalidade da análise, introduziu-se alguns filtros, dessa forma eliminou-se os indivíduos sem observação de renda, com salários menores do que $R \$ 500,00$ e salários maiores do que $\mathrm{R} \$ 50.000,00$, bem como indivíduos com menos de 15 anos e com mais de 90 anos, além disso, eliminou-se as informações do salário por hora de trabalho que são menores do que $\mathrm{R} \$ 3,00$ e maiores do que RS 300,00. Esse recorte é necessário para retirarmos da amostra as observações que se referem às pessoas que não possuem uma ocupação no mercado de trabalho. Portanto, a base de dados contém 21.011 informações.

Com relação ao processo para montar a base de dados, é importante levar em conta a discussão que envolve sobre o tema empreendedorismo, ou seja, as definições gerais sobre o que a literatura considera um indivíduo empreendedor. Dessa forma, Parker (2009) aponta que não há consenso sobre a definição do termo empreendedorismo, além disso destaca que alguns pesquisadores identificam empreendedores como empresários de pequenas empresas ou trabalhadores independentes, outros estabelecem que empreendedores são empresários que empregam outros trabalhadores. Portanto, no contexto deste estudo utiliza-se o primeiro conceito apontado, e a variável dependente $Y_{i}$ "empreendedor" foi criada a partir da posição de ocupação dos indivíduos economicamente ativos, essa variável assume o valor "um" caso o indivíduo seja empregador ou autônomo e "zero" caso seja assalariado. Sendo tanto empregadores como trabalhadores por conta própria inseridos na variável dependente. Em outras palavras, objetiva-se explicar, através do modelo probit, quais são as características sociais e econômicas que levam um indivíduo a decidir em ser ou não empreendedor, neste caso trabalhador independente e empregador.

Para estimar as equações de salários é necessário obter a variável salário por hora de trabalho, que não está no banco de dados da PNAD (2015), portanto faz-se necessário calcular. Primeiro, criou-se a variável horas trabalhadas em um mês,

\footnotetext{
${ }^{5}$ Base de dados mais recente disponível até julho de 2019.
} 
multiplicando as horas trabalhadas semanalmente pelo número médio de semanas em um mês $(4,34)$, assim obtém-se as horas trabalhadas mensalmente. Por último, divide o salário mensal pelas horas trabalhadas em um mês, chegando-se ao salário por hora trabalhada. Por fim, aplica-se o logaritmo na variável "salário/hora".

Com relação às variáveis independentes escolhidas, ou seja, as características socioeconômicas e demográficas que utilizamos para explicar a variável dependente " $Y_{i}$ ", escolheu-se as variáveis com base no estudo de Menezes, Queiroz \& Feijo (2015), com a finalidade de obter efeitos comparativos. Portanto, as variáveis independentes utilizadas são: sexo, raça, idade, idade ao quadrado, anos de estudo, estado civil, se é chefe de família, número de filhos, pensionista, aposentado, variáveis de renda, se reside em área urbana ou agrícola e se é morador de metrópole.

Na sequência faz-se a apresentação das estatísticas descritivas das variáveis utilizadas, tabela 01 . Onde temos que somente idade, idade ao quadrado, número de filhos, educação, salário e salário/hora não são variáveis binárias.

Tabela 01 - Estatísticas descritivas

\begin{tabular}{|c|c|c|c|c|c|}
\hline Variáveis & Descrição & Média & Desvio-padrão & Mínimo & Máximo \\
\hline Empreendedor & Dummy & 0,279 & 0,448 & 0 & 1 \\
\hline Assalariado & Dummy & 0,720 & 0,448 & 0 & 1 \\
\hline Sexo & $\begin{array}{l}\text { Homem: } 1 \\
\text { Mulher: } 0\end{array}$ & 0,592 & 0,491 & 0 & 1 \\
\hline Raça & $\begin{array}{l}\text { Branco: } 1 \\
\text { Demais: } 0\end{array}$ & 0,774 & 0,418 & 0 & 1 \\
\hline Idade & Anos & 39,16 & 13,29 & 15 & 90 \\
\hline Idade $^{2}$ & & 1709,9 & 1119,6 & 225 & 8100 \\
\hline Educação & Em anos de estudo & 10,47 & 3,88 & 1 & 16 \\
\hline Estcivil & $\begin{array}{l}\text { Casado: } 1 \\
\text { Demais: } 0\end{array}$ & 0,0395 & 0,194 & 0 & 1 \\
\hline Chefe & Dummy & 0,510 & 0,499 & 0 & 1 \\
\hline № Filhos & & 0,373 & 0,779 & 0 & 11 \\
\hline Pensionista & Dummy & 0,015 & 0,124 & 0 & 1 \\
\hline Aposentado & Dummy & 0,066 & 0,248 & 0 & 1 \\
\hline Renda aluguel & Dummy & 0,012 & 0,109 & 0 & 1 \\
\hline Urbana & Dummy & 0,897 & 0,303 & 0 & 1 \\
\hline Metrop & Dummy & 0,448 & 0,497 & 0 & 1 \\
\hline Salário & Em Reais de 2015 & 2183 & 2492 & 500 & 50000 \\
\hline Salário/hora & Em Reais de 2015 & 14,47 & 21,25 & 3 & 297 \\
\hline Observações & & & & & 21.011 \\
\hline
\end{tabular}

Fonte: elaborado pelos autores com base nos dados da PNAD 2015. 


\section{ANÁLISE E DISCUSSÃO DOS RESULTADOS}

Nesta seção serão apresentados os resultados obtidos através da estimação do modelo de Heckman em duas etapas. A primeira etapa estimada por um probit apresenta os coeficientes cuja interpretação refere-se apenas ao seu sinal, portanto, com o intuito de gerar mais informações foram adicionados os efeitos marginais. A segunda etapa é exibida na sequência e se refere a estimação da equação de rendimentos de Heckman, cuja finalidade é corrigir viés de seleção.

De um modo geral, os resultados estimados abaixo apresentam coeficientes com sinais de acordo com o esperado, o resultado do teste chi-quadrado demonstra que as variáveis explicativas são conjuntamente importantes para explicar a variável dependente (empreendedor). Portanto, constata-se que as variáveis sexo, raça, idade, idade ao quadrado, educação, estado civil, chefe de família, se possui renda de aluguel, se reside em área urbana e se reside em região metropolitana são estatisticamente significativas. Além disso, cabe ressaltar que o modelo apresentou um bom ajustamento, uma vez que foi feita uma tabela de classificação preditiva na qual demonstrou que o modelo prevê corretamente $73,36 \%$ dos eventos. A seguir a Tabela 02 que indica os resultados obtidos por meio de um modelo probit, e na sequência os comentários.

Tabela 02 - Condicionantes do empreendedorismo na região Sul do Brasil

\begin{tabular}{|c|c|c|}
\hline \multirow[t]{2}{*}{ Variáveis } & \multicolumn{2}{|c|}{ Probit } \\
\hline & Coeficiente & Efeito Marginal \\
\hline \multirow[t]{2}{*}{ Sexo } & $0.2656^{\star * *}$ & $0.0815^{\star \star \star}$ \\
\hline & $(0.0319)$ & $(0.0098)$ \\
\hline \multirow[t]{2}{*}{ Raça } & $0.1773^{\star \star \star}$ & $0.0544^{\star \star \star}$ \\
\hline & $(0.0285)$ & $(0.0086)$ \\
\hline \multirow[t]{2}{*}{ Idade } & $0.0372^{* \star *}$ & $0.0114^{\star * *}$ \\
\hline & $(0.0049)$ & $(0.0015)$ \\
\hline \multirow[t]{2}{*}{ Idade $^{2}$} & -0.0001 & -0.0000 \\
\hline & $(0.0001)$ & $(0.0000)$ \\
\hline \multirow[t]{2}{*}{ De 5 a 8 anos de estudo } & $0.0780^{\star *}$ & $0.0239^{* *}$ \\
\hline & $(0.0365)$ & $(0.0112)$ \\
\hline \multirow[t]{2}{*}{ De 9 a 12 anos de estudo } & -0.0173 & -0.0053 \\
\hline & $(0.0332)$ & $(0.0102)$ \\
\hline \multirow[t]{2}{*}{ Mais de 12 anos de estudo } & $0.2045^{\star \star \star}$ & $0.0628^{\star * *}$ \\
\hline & $(0.0397)$ & $(0.0122)$ \\
\hline \multirow[t]{2}{*}{ Estado civil } & -0.0861 & -0.0264 \\
\hline & $(0.0587)$ & $(0.0180)$ \\
\hline
\end{tabular}




\begin{tabular}{|c|c|c|}
\hline Chefe de família & $0.1014^{\star * \star}$ & $0.0311^{* * *}$ \\
\hline & $(0.0227)$ & $(0.0070)$ \\
\hline \multirow[t]{2}{*}{ Número de filhos } & $0.0299^{*}$ & $0.0092^{*}$ \\
\hline & $(0.0179)$ & $(0.0055)$ \\
\hline \multirow[t]{2}{*}{ Se é pensionista } & $0.2432^{\star \star \star}$ & $0.0746^{\star \star \star}$ \\
\hline & $(0.0941)$ & $(0.0289)$ \\
\hline \multirow[t]{2}{*}{ Se é aposentado } & -0.0527 & -0.0162 \\
\hline & $(0.0494)$ & $(0.0151)$ \\
\hline \multirow[t]{2}{*}{ Renda de aluguel } & $0.4698^{\star * *}$ & $0.1441^{* * *}$ \\
\hline & $(0.0909)$ & $(0.0278)$ \\
\hline \multirow[t]{2}{*}{ Se reside em área urbana } & $-0.4471^{\star \star *}$ & $-0.1372^{* \star *}$ \\
\hline & $(0.0474)$ & $(0.0143)$ \\
\hline \multirow[t]{2}{*}{ Se reside em área metropolitana } & $-0.1292^{\star \star \star}$ & $-0.0396^{* * *}$ \\
\hline & $(0.0247)$ & $(0.0076)$ \\
\hline \multirow[t]{2}{*}{ Constante } & $-1.9129^{\star * *}$ & \\
\hline & $(0.1080)$ & \\
\hline Observações & 21.011 & \\
\hline Log-verossimilhança & $-11246,455$ & \\
\hline Teste de Wald & $x_{i}^{2}=3037,56$ & \\
\hline Classificação preditiva & $73,9 \%$ & \\
\hline
\end{tabular}

Fonte: Elaborado pelos autores, a partir da PNAD 2015. Legenda: os desvios-padrões são robustos à heterocedasticidade. * parâmetros significativos à $10 \%$; ** parâmetros significativos à $5 \%$; *** parâmetros significativos à $1 \%$.

Com relação à decisão ocupacional da região Sul, temos que os homens possuem $8,15 \%$ a mais de chance, do que as mulheres, de serem empreendedores. O que corrobora com Wit e Winder (1989), Welsch e Young (1984) e Cromie (1987). Além disso, a raça e a idade também aumentam a chance, sendo que um indivíduo de cor branca tem $5,44 \%$ a mais na chance de se tornar empreendedor. Portanto, os resultados com relação à raça estão de acordo com os resultados de Borjas e Bronars (1989) e Clark e Drinkwater (1998). Bem como um ano a mais na idade aumenta a chance de o indivíduo ser empreendedor em 1,14\%, estando de acordo com o apresentado por Parker (2009). Todavia, a chance de ser empreendedor cresce a taxas decrescentes com a idade, como indica o sinal negativo da idade ao quadrado.

Os anos de estudo apresentam baixa relação com a ocupação empreendedora, esse resultado se justifica com o efeito ambíguo que essa variável tem, como apresentado por Camargo Neto et al. (2017), em que os autores mostram que a 
educação aumenta a probabilidade de um indivíduo ser empregador, mas reduz a chance de ser um autônomo. Tendo isso em vista, estimou-se os anos de estudo com três dummies, a primeira que representa indivíduos com 5 a 8 anos de estudo afeta positivamente a probabilidade de empreender em 2,39\%, a segunda dummy (9 a 12 anos) não captou efeito estatisticamente significativo, e a terceira dummy que representa indivíduos com mais de 12 anos de estudo aumenta a probabilidade de empreender em 6,28\%.

Com relação à posição de ocupação na família, ser chefe de família na região Sul aumenta a probabilidade de o indivíduo ter um negócio próprio em 3,11\% e ser casado não captou efeito estatisticamente significativo. Além disso, ter uma renda de aluguel aumenta a chance em $14,41 \%$, bem como ser pensionista aumenta a chance de empreender em $7,46 \%$.

Ao se tratar dos aspectos regionais, residir em área urbana na região Sul reduz a probabilidade de um indivíduo ter um negócio em 13,72\%, o que diverge do estudo de Acs, Bosma e Sternberg (2008), no entanto coincide com o resultado encontrado por Menezes, Queiroz e Feijo (2015) para o Brasil como um todo. Além disso, residir em uma área metropolitana na região Sul reduz a chance de ser empreendedor em $3,96 \%$, o que corrobora com o resultado proposto por Menezes, Queiroz e Feijo (2015).

Segundo Parker (2009), do ponto de vista da economia do empreendedorismo é interessante saber se os empreendedores ganham relativamente mais que os assalariados, dado que as escolhas são feitas em função da maximização de suas utilidades. Analisando as estatísticas da amostra em estudo, temos que o salário médio dos empreendedores na região Sul é $\mathrm{R} \$ 3.047$ com uma idade média de 45 anos. Já para o empregado o salário médio é de $\mathrm{R} \$ 1.849$ com uma idade média de 37 anos. Ou seja, podemos notar que o empreendedor ganha em média $61 \%$ a mais que o indivíduo que trabalha como assalariado na região Sul do Brasil. Para o Brasil temos que o salário médio dos empreendedores é $R \$ 2.477$, bem como para os assalariados é $R \$$ 1.683. Então para completar a análise a tabela 4 exibe as estimativas para as equações de rendimento, a qual explica a escolha pela ocupação empreendedora em função dos ganhos relativos ao trabalho assalariado.

A tabela 03 apresenta os resultados da estimação da equação de rendimentos. É importante levar em conta que o modelo de Heckman mostrou resultados mais robustos que os obtidos pela estimação por Ordinary Least Squares (OLS), já que os coeficientes das variáveis $\lambda_{1}$ e $\lambda_{2}$ foram estatisticamente significativos. Portanto, 0 
método mostrou-se necessário para a correção do viés de seleção da amostra, tornando consistentes as estimativas realizadas para os condicionantes dos rendimentos dos empreendedores e assalariados.

Tabela 03 - Equações de Salário estimadas pelo Método de Heckman e OLS

\begin{tabular}{|c|c|c|c|c|}
\hline \multirow[t]{2}{*}{ Variáveis } & \multicolumn{2}{|c|}{ Empreendedor } & \multicolumn{2}{|c|}{ Assalariado } \\
\hline & Heckman & OLS & Heckman & OLS \\
\hline \multirow[t]{2}{*}{ Sexo } & $-0.1030^{\star \star *}$ & $0.0717^{* *}$ & $0.1072^{\star \star \star}$ & $0.1760^{\star \star \star}$ \\
\hline & $(0.0392)$ & $(0.0311)$ & $(0.0160)$ & $(0.0112)$ \\
\hline \multirow[t]{2}{*}{ Raça } & -0.0198 & $0.1092^{\star \star \star}$ & $0.0478^{* * *}$ & $0.0970^{\star * *}$ \\
\hline & $(0.0299)$ & $(0.0236)$ & $(0.0138)$ & $(0.0104)$ \\
\hline \multirow[t]{2}{*}{ Idade } & $-0.0351^{* * *}$ & -0.0062 & $0.0101^{* * *}$ & $0.0138^{* * *}$ \\
\hline & $(0.0058)$ & $(0.0043)$ & $(0.0023)$ & $(0.0023)$ \\
\hline \multirow[t]{2}{*}{ Idade $^{2}$} & $0.0003^{* \star *}$ & $0.0002^{\star \star \star}$ & $-0.0001^{* * *}$ & -0.0000 \\
\hline & $(0.0000)$ & $(0.0000)$ & $(0.0000)$ & $(0.0000)$ \\
\hline \multirow[t]{2}{*}{$\begin{array}{l}\text { De } 5 \text { a } 8 \text { anos de } \\
\text { estudo }\end{array}$} & $0.0580^{*}$ & $0.1172^{\star * \star}$ & $0.1061^{* * *}$ & $0.1271^{* * *}$ \\
\hline & $(0.0313)$ & $(0.0307)$ & $(0.0172)$ & $(0.0169)$ \\
\hline \multirow[t]{2}{*}{$\begin{array}{l}\text { De } 9 \text { a } 12 \text { anos de } \\
\text { estudo }\end{array}$} & $0.3371^{* \star *}$ & $0.3231^{* * *}$ & $0.3026^{\star * *}$ & $0.2982^{\star * *}$ \\
\hline & $(0.0323)$ & $(0.0329)$ & $(0.0178)$ & $(0.0178)$ \\
\hline \multirow[t]{2}{*}{$\begin{array}{l}\text { Mais de } 12 \text { anos de } \\
\text { estudo }\end{array}$} & $0.7410^{\star \star \star}$ & $0.8915^{\star \star \star}$ & $0.7971^{\star * *}$ & $0.8539^{* * *}$ \\
\hline & $(0.0457)$ & $(0.0421)$ & $(0.0266)$ & $(0.0243)$ \\
\hline \multirow[t]{2}{*}{ Estado civil } & 0.0804 & 0.0085 & -0.0094 & -0.0365 \\
\hline & $(0.0557)$ & $(0.0548)$ & $(0.0246)$ & $(0.0249)$ \\
\hline \multirow[t]{2}{*}{ Chefe de família } & 0.0346 & $0.1188^{\star * *}$ & $0.0767^{\star \star *}$ & $0.1116^{\star \star \star}$ \\
\hline & $(0.0233)$ & $(0.0199)$ & $(0.0111)$ & $(0.0094)$ \\
\hline \multirow[t]{2}{*}{ Número de filhos } & -0.0090 & 0.0050 & -0.0090 & -0.0045 \\
\hline & $(0.0201)$ & $(0.0200)$ & $(0.0069)$ & $(0.0069)$ \\
\hline \multirow[t]{2}{*}{$\begin{array}{l}\text { Se reside em área } \\
\text { urbana }\end{array}$} & $0.5123^{\star * *}$ & $0.1952^{* * *}$ & $0.2607^{* * *}$ & $0.1168^{* * *}$ \\
\hline & $(0.0581)$ & $(0.0334)$ & $(0.0314)$ & $(0.0214)$ \\
\hline \multirow[t]{2}{*}{$\begin{array}{l}\text { Se reside em área } \\
\text { metropolitana }\end{array}$} & $0.1065^{\star \star \star}$ & 0.0084 & $0.0872^{\star * *}$ & $0.0506^{* * *}$ \\
\hline & $(0.0304)$ & $(0.0268)$ & $(0.0157)$ & $(0.0143)$ \\
\hline \multirow[t]{2}{*}{$\lambda_{1}$} & $-3.9697^{* * *}$ & & & \\
\hline & $(0.5467)$ & & & \\
\hline \multirow[t]{2}{*}{$\lambda_{2}$} & & & $-1.4043^{\star * *}$ & \\
\hline & & & $(0.2632)$ & \\
\hline Constante & $5.1300^{\star * *}$ & $1.6671^{* \star *}$ & -0.0979 & $1.0547^{* \star *}$ \\
\hline
\end{tabular}




\begin{tabular}{c|c|c|c|c}
\hline & $(0.4825)$ & $(0.1026)$ & $(0.2259)$ & $(0.0485)$ \\
\hline Observações & & & & \\
\hline $\mathrm{R}^{2}$ & 6,222 & 6,222 & 14,789 & 14,789 \\
\hline
\end{tabular}

Fonte: Elaborado pelos autores, a partir da PNAD 2015. Legenda: os desvios-padrões são robustos à heterocedasticidade para as estimativas OLS. Para as estimações de Heckman desvio padrão robustos obtidos por bootstrap com 1000 replicações. * parâmetros significativos à 10\%; ** parâmetros significativos à $5 \% ;{ }^{* * *}$ parâmetros significativos à $1 \%$.

Os resultados da tabela 03 permitem fazer a seguinte análise. As mulheres empreendedoras ganham em média mais do que os homens empreendedores, ou seja, a correção do viés de seleção permitiu captar tal efeito, tendo em vista que na regressão sem correção o efeito é contraditório. O que reforça esse resultado são as estatísticas apontadas na Tabela 04, onde as mulheres empreendedoras ganham em média $R \$ 20,13$ por hora de trabalho, e os homens empreendedores ganham em média $\mathrm{R} \$ 19,85$ por hora de trabalho. Em contrapartida, os homens assalariados ganham em média mais do que as mulheres assalariadas, $R \$ 18,18$ e $R \$ 17,89$, respectivamente.

Tabela 04 - Salário por hora de trabalho na região Sul do Brasil

\begin{tabular}{l|l|l}
\hline Salário/hora & Observações & Média (R\$) \\
\hline Homem empreendedor & 4.365 & 19,85 \\
\hline Mulher empreendedora & 1.857 & 20,13 \\
\hline Homem assalariado & 8.714 & 18,18 \\
\hline Mulher assalariada & 6.075 & 17,89 \\
\hline Branco empreendedor & 5.115 & 20,98 \\
\hline Não branco empreendedor & 1.107 & 15,10 \\
\hline Branco assalariado & 11.257 & 13,13 \\
\hline Não branco assalariado & 3.532 & 10,00 \\
\hline Empreendedor com 5 a 8 anos de estudo & 1.658 & 14,06 \\
\hline Empreendedor com 9 a 12 anos de estudo & 2.001 & 37,41 \\
\hline Empreendedor com mais de 12 anos de estudo & 1.381 & 9,34 \\
\hline Assalariado com 5 a 8 anos de estudo & 3.381 & 10,47 \\
\hline Assalariado com 9 a 12 anos de estudo & 6.837 & 21,87 \\
\hline Assalariado com mais de 12 anos de estudo & 2.952 & \\
\hline
\end{tabular}

Fonte: Elaborado pelos autores, a partir da PNAD 2015.

Os indivíduos da cor branca que optam pela ocupação empreendedora também possuem salários mais elevados do que aqueles que optam pela ocupação assalariada. Portanto, esses resultados corroboram com o encontrado por Menezes, Queiroz e Feijo (2015) para o Brasil. No entanto, não foi possível corrigir o problema 
de viés de seleção, já que a variável não foi estatisticamente significativa na equação de rendimentos com correção, mas é possível notar a diferença pela média do salário por hora de trabalho na Tabela 4.

Com relação aos retornos dos níveis de escolaridade, destaca-se sobre a importância em relação aos rendimentos. Como pode-se notar na Tabela 3, quanto mais anos de estudo um indivíduo concluí maior são os retornos nos rendimentos. Além disso, nota-se que os empreendedores auferem mais que os assalariados para todos os níveis de instrução, evidenciando a importância da educação para os rendimentos quando se considera a ocupação empreendedora (autônomos e empregadores). No entanto, as estimações das equações de salário pelo modelo proposto por Heckman (1979) não apresentaram eficiência na correção do viés de seleção para a educação.

Em se tratando da condição familiar, ser chefe de família afeta positivamente os rendimentos dos indivíduos, já que a variável é estatisticamente significativa. Além disso, tem-se que os empreendedores possuem rendimentos mais elevados do que os assalariados na região Sul do Brasil. O que corrobora com o encontrado por Menezes, Queiroz e Feijo (2015) para o Brasil.

Residir em áreas urbanas aufere maiores salários do que residir em áreas rurais, além disso, quando corrigido o viés de seleção pelo método de Heckman, o efeito é ainda maior do que na equação de salários sem correção. Entre os indivíduos que residem em áreas urbanas, os empreendedores também possuem salários maiores do que os assalariados. O fato de indivíduos residirem em uma região metropolitana, na região Sul, aufere ganhos mais elevados aos empreendedores em relação aos assalariados. Este resultado diverge com 0 proposto por Menezes, Queiroz e Feijo (2015) para o Brasil. Além disso, é possível notar que a diferença entre a média de salários, em regiões metropolitanas, dos empreendedores e assalariados da região Sul é de $\mathrm{R} \$ 1.337$, bem como essa diferença para o Brasil é de $R \$ 885$. Dessa forma, pode-se notar que o salário médio de empresários em metrópoles da região sul é maior do que para o Brasil. No entanto, os assalariados da região sul possuem um salário médio menor do que para o país como um todo. Essas informações também são encontradas quando analisamos o salário médio por hora de trabalho, de forma que um empreendedor metropolitano na região sul ganha $R \$ 3,05$ a mais, por hora trabalhada, do que um empreendedor metropolitano no Brasil. Para os assalariados metropolitanos da 
região sul, tem-se que possuem um salário por hora trabalhada de $R \$ 0,18$ maior, em relação aos assalariados metropolitanos do Brasil.

O sinal negativo da taxa inversa de Mills $\lambda_{1}$ sugere que o empreendedor aufere, em média, remuneração maior do que um indivíduo aleatoriamente distribuído na amostra e que a arbitragem foi consistente (MADDALA, 1986). Assim como o resultado encontrado acima corrobora com o proposto por Menezes, Queiroz e Feijo (2015) e por Taylor (1996), onde através de resultados empíricos, sugere que os indivíduos são atraídos pelo auto-emprego por causa dos maiores salários esperados, em relação ao emprego assalariado e pela isenção de restrições gerenciais. Portanto, dá suporte aos fundamentos microeconômicos, o qual argumenta que a escolha da ocupação é baseada na maximização da utilidade.

Por fim, para completar a análise, faz-se o cálculo do diferencial de rendimentos entre empreendedores e assalariados considerando a hipótese de contrafactual. Os assalariados ganhariam mais se estivessem ocupados como empreendedores, e estes últimos ganhariam menos se estivessem trabalhando como assalariados, indicando que os empreendedores acertaram em trabalhar como empreendedores (ver Tabela 05).

Tabela 05 - Cálculo do diferencial de rendimentos entre empreendedores e assalariados

\begin{tabular}{l|l|c}
\hline & \multicolumn{2}{|c}{ Logaritmo do salário-hora } \\
\hline & Assalariados & Empreendedores \\
\hline (A) factual & 0,9354 & 4,8429 \\
\hline (B) contrafactual & 5,0588 & 0,9289 \\
\hline diferença (A-B) & $-4,1234^{\star \star *}$ & $3,9140^{\star * *}$ \\
\hline Total & 0,9335 & 4,9949 \\
\hline Fonte: Elaborado pelo autor a partir dos microdados da PNAD 2015.
\end{tabular}

Legenda: *** parâmetros significativos à $1 \%$.

Mas se os assalariados ganhariam mais, então o que os impede de empreender? Segundo Blanchflower e Oswald (1998) a renda disponível para começar um negócio é um dos fatores importantes para que um assalariado troque a sua ocupação para empreendedor. Além disso, os autores evidenciam que a psicologia aparentemente não desempenha um papel chave na determinação de quem torna-se um empreendedor. Huber, Sloof e Van Praag (2012) buscam analisar a eficácia da educação inicial no empreendedorismo, para isso realizam um experimento de campo randomizado para avaliar um programa de ensino de empreendedorismo, e concluem que o programa tem um efeito positivo robusto sobre as habilidades empreendedoras não-cognitivas. 
Jiménez et al. (2015) mostram que o ensino terciário aumenta o empreendedorismo formal como consequência da maior autoconfiança, menor risco percebido e maior capital humano. Ao mesmo tempo, o ensino superior também tem um efeito negativo sobre o empreendedorismo informal, uma vez que aumenta a consciência e a sensibilidade às possíveis repercussões negativas deste tipo de atividades. Assim como Camargo Neto et al. (2017), que apontam um aumento na chance de um indivíduo ser empregador com o aumento da escolaridade, bem como a redução na probabilidade de ser autônomo.

Além das questões apontadas, o conjunto de regras sociais, leis e estrutura econômica de um país podem influenciar na decisão empreendedora, tendo em vista que um país pode ter um ambiente mais propicio para o empreendedorismo do que outros.

\section{Considerações Finais}

A proposta deste estudo foi realizar uma análise estimando um modelo probabilístico para determinar as determinantes do empreendedorismo para a região Sul do Brasil, assim como estimou-se as equações de rendimentos através do modelo proposto por Heckman (1979), onde foi possível chegar ao resultado geral de que os salários são relevantes na escolha ocupacional do auto-emprego, denominado como empreendedor neste estudo.

Conforme mostram os resultados, as variáveis: anos de estudo, sexo, raça, idade, idade ${ }^{2}$, educação, chefe de família, estado civil, se é aposentado, assim como renda de aluguel, área urbana e metrópole são estatisticamente significativas no modelo probit, o que permite inferir que ambas são condicionantes do empreendedorismo na região Sul do Brasil, de forma que através dos efeitos marginais calculados adquire-se os percentuais que cada uma delas representa na escolha ocupacional empreendedora. Além disso, os empreendedores ganham mais do que os assalariados para todos os níveis de educação, bem como as mulheres empreendedoras auferem maiores rendimentos do que os homens empreendedores na região Sul do Brasil, e por fim, os empreendedores acertaram na arbitragem ao ganharem mais do que um indivíduo aleatoriamente distribuído na amostra, como evidenciado pelo controle para viés de seleção. 


\section{REFERÊNCIAS}

ACS, Z.; ARMINGTON, C. Employment Growth and Entrepreneurial Activity in Cities. Regional Studies, v. 38, n. 8, p. 911-927, nov. 2004.

ACS, Z. J.; BOSMA, N.; STERNBERG, R. The entrepreneurial advantage of world cities: evidence from global entrepreneurship monitor data. Jena economic research papers, 2008.

AUDRETSCH, D. B.; THURIK, A. R. Capitalism and democracy in the 21st century: from the managed to the entrepreneurial economy. In: Mueller D.C., Cantner U. (eds) Capitalism and Democracy in the 21st Century. Physica, Heidelberg, 2001.

BLANCHFLOWER, D. G.; OSWALD, A. J. What Makes an Entrepreneur?. Journal of Labor Economics, 1998.

BOCK, J. H.; WAGNER, M. Necessity and Opportunity Entrepreneurs in Germany:

Characteristics and Earnings Differentials. Schmalenbach Business Review. Vol 62, 2, p. 154-174, 2010.

BORJAS, G. J.; BRONARS, S. Consumer discrimination and self-employment. The Journal of political economy, 1989.

IBGE. Instituto Brasileiro de Geografia e Estatística. Disponível em: < https://www.ibge.gov.br >. Acesso em: 23, fevereiro, 2019.

CAMARGO NETO, R.; BARBOSA, M.; QUEIROZ, V. S.; MENEZES, G. Condicionantes do Empreendedorismo no Brasil: uma análise regional. Revista Brasileira de Estudos

Regionais e Urbanos (RBERU), v. 11, n. 4, p. 20, 2017.

CARREE, M.; THURIK, R. Understanding the role of entrepreneurship for economic growth. The Handbook of Entrepreneurship and Economic Growth, Cheltenham, Elgar, ix-xix, 2005.

CLARK, K.; DRINKWATER, S. Ethnicity and Self-Employment in Britain. Oxford Bulletin of Economics and Statistics, v. 60, n. 3, p. 383-407, 1 ago. 1998.

CROMIE, S. Similarities and Differences between Women and Men Business Proprietorship. International Small Business Journal, 5(3), 43-60, 1987.

DE ALMEIDA, F. M.; SEDIYAMA, G. A. S.; SANTIAGO, F. A. A Contribuição do Empreendedorismo para o Crescimento Econômico dos Estados Brasileiros. Enaber, 2015.

FRITSCH, M.; MUELLER, P. The effect of new business formation on regional development over time: the case of Germany. Small Business Economics, v. 30, n. 1, p. 15-29, 26 nov. 2007.

GREENE, W. H. Econometric Analysis. 7th ed. Ed. Pearson, 2012.

HECKMAN, J. J. Sample Selection Bias as a Specification Error. Econometrica, v. 47, n. 1, p. 153-161, 1979.

HUBER, L. R.; SLOOF, R.; VAN PRAAG, M. The effect of early entrepreneurship education: Evidence from a randomized field experiment. IZA Discussion Papers 6512, Institute for the Study of Labor (IZA), 2012.

JIMÉNEZ, A.; PALMERO-CÁMARA, C.; GONZÁLEZ-SANTOS, M.; GONZÁLEZ-BERNAL, J; JIMÉNEZ-EGUIZÁBAL, J. The impact of educational levels on formal and informal entrepreneurship. BRQ Business Research Quarterly, v. 18, n. 3, p. 204-212, jul. 2015.

KASSOUF, A. L. The Wage Rate Estimation Using the Heckman Procedure. Brazilian Review of Econometrics, v. 14, n. 1, p. 89, 1 abr. 1994. 
LAZEAR, E. P. Entrepreneurship. Journal of Labor Economics, Volume 23, Number 4, 2005.

LEE, L.-F. Generalized Econometric Models with Selectivity. Econometrica, v. 51, n. 2, p. 507-512, 1983.

LORZ, M. The impact of entrepreneurship education on entrepreneurial intention.

Dissertation Doctor - Germany: University of St. Gallen, 2011.

MADDALA, G. S. Chapter 28 Disequilibrium, self-selection, and switching models. In:

Handbook of Econometrics. Elsevier, v. 3p. 1633-1688, 1986.

MENEZES, G.; DOS SANTOS QUEIROZ, V.; FEIJO, F. T. Determinantes do

Empreendedorismo no Brasil: uma análise da escolha ocupacional e dos rendimentos.

ENABER, 2015.

MINCER, J. Education, income, and human behavior. NBER. New York: McGraw-Hill, p 71 94, 1974.

OOSTERBEEK, H.; VAN PRAAG, M.; IJSSELSTEIN, A. The impact of entrepreneurship education on entrepreneurship skills and motivation. European Economic Review, v. 54, n. 3, p. 442-454, abr. 2010.

PARKER, S. C. The economics of entrepreneurship. Cambridge, UK; New York: Cambridge University Press, 2009.

PRAAG, C. M. V.; VERSLOOT, P. H. What is the Value of entrepreneurship? A Review of Recent Research. n. IZA DP No. 3014, p. 43, 2007.

REES, H.; SHAH, A. An empirical analysis of self-employment in the UK. Journal of applied econometrics, v. 1, n. 1, p. 95-108, 1986.

TAMVADA, V. J. P. Entrepreneurship and Economic Development. Essays on

Entrepreneurship and Economic Development. Tese de doutorado - New Delhi: der Universität Göttingen, 2007.

TAYLOR, M. P. Earnings, Independence or Unemployment: Why become self-employed?

Oxford Bulletin of Economics and Statistics, v. 58, n. 2, p. 253-266, 1 maio 1996.

WELSCH, H.; YOUNG, E. Male and Female Entrepreneurial Characteristics and Behaviours: A Profile of Similarities and Differences. International Small Business Journal, vol 2, issue 4, p 11-20, 1984.

WIT, G. D.; WINDER, F. A. A. M. V. An empirical analysis of self-employment in the Netherlands - Springer. Small Business Economics, v. Volume 1, Issue 4, pp 263-272, 1989.

\section{Notas de Autor}

\section{CONTRIBUIÇÃO DE AUTORIA}

Roque Pinto de Camargo Neto - Concepção. Coleta de dados, Análise de dados, Elaboração do manuscrito, revisão e aprovação da versão final do trabalho.

Vivian dos Santos Queiroz Orellana - Participação ativa da discussão dos resultados; Revisão e aprovação da versão final do trabalho.

Gabrielito Rauter Menezes - Análise de dados, Elaboração do manuscrito, revisão e aprovação da versão final do trabalho.

FINANCIAMENTO

Não se aplica. 


\section{APROVAÇÃO DE COMITÊ DE ÉTICA EM PESQUISA}

Não se aplica.

\section{CONFLITO DE INTERESSES}

Informar conflitos de interesse: financeiros, pessoais, entre possíveis revisores e editores, possíveis vieses temáticos. Para mais informações: https://www.abecbrasil.org.br/arquivos/whitepaper_CSE.pdf

\section{LICENÇA DE USO}

Este artigo está licenciado sob a Licença Creative Commons CC-BY-NC. Com essa licença você pode compartilhar, adaptar, criar para qualquer fim, sem uso comercial e desde que atribua a autoria da obra.

\section{HISTÓRICO}

Recebido em: 11-07-2019

Aprovado em: 08-06-2020 